\title{
The interaction of katabatic winds and the formation of blue-ice areas in East Antarctica
}

\author{
Michiel van den Broeke and Richard Bintanja \\ Institute for Marine and Atmospheric Research Utrechl, P.O. Box 80.005, 3508 TA Utrecht, The Netherlands
}

\begin{abstract}
Blue-ice areas (BIAs) are an extreme example of a local massbalance gradient and are furthermore reasonably stable in time and space owing to local feed-back mechanisms. A meteorological experiment, performed in and around a blue-ice area in Dronning Maud Land, East Antarctica, showed that during driftingsnow conditions surface wind speed over the blue ice behind the mountain barrier is equal to that away from the mountains, when corrected for surface roughness and stability. This implies that use of diagnostic katabatic wind models to estimate divergence of drifting snow can be extended to the situation where nunataks are involved in preventing the drifting snow from passing, which is the case for most BIAs. A diagnostic model is tested for a two-dimensional profile in Terre Adélie, after which it is applied to entire East Antarctica. The present order-of-magnitude estimate shows that areas sensitive to blue-ice formation appear where precipitation is low and mean annual wind speed is high, i.e. in Dronning Maud Land and the drainage basin of Lambert Glacier. The results appeared to be especially sensitive to a change in inversion strength: a decrease in inversion strength weakens the katabatic flow, and thus the amount of snowdrift transport, reducing the area where BIAs can develop.
\end{abstract}

\section{INTRODUCTION}

As a boundary condition for determining the present integrated mass balance of the Antarctic ice sheet, the surface mass balance is of great interest to modern glaciology (Oerlemans, 1993). However, many processes determine the eventual amount of snow deposited in a local "year layer" as observed in an Antarctic firn core, provided that no melting occurs: erosion and deposition of drifting snow, precipitation, sublimation and deposition. Counting of annual layers using the seasonal cycle of oxygen-isotope ratios and other chemical components in the snow is hindered considerably when processes other than precipitation are active. Katabatic winds influence the surface mass balance in three different ways. They determine the turbulent exchange of latent heat from the surface into the air and vice versa, i.e. the amount of sublimation/deposition. They also redistribute the snow, especially in the escarpment and coastal areas of the continent (0-2000 ma.s.l.) where wind speeds are considerably higher than at inland locations owing to the steeper surface slopes. Finally, a possible large mass loss occurs when blowing snow sublimates in the air where it is suspended. This effect becomes especially important if the material remains in suspension for a longer period (Schmidt, 1986).

Divergence of drifting- and blowing-snow transport, although probably of minor importance to the integrated mass budget of Antarctica (Loewe (1970) estimated that $6 \%$ of the yearly accumulation is blown into the sea), cannot be disregarded for the surface mass balance on a local or regional scale. This is indicated by the large scatter in stake measurements in the scale of several metres to kilometres everywhere on the continent. The temporal distribution also exhibits large variations from year to year, as indicated by analysis of shallow firn cores where sometimes whole years are missing from the icecore record.

An extreme example of local mass-balance gradients can be found in the vicinity of blue-ice areas (BIAs), where the snow cover has been removed and the old glacier ice surfaces. BIAs therefore provide an excellent opportunity to study the (feed-back) processes that determine large variations in mass balance on a small scale of just several kilometres. A meteorological experiment was performed in and around a small BIA $\left(10 \mathrm{~km}^{2}\right)$ in Dronning Maud Land during the austral summer of 1992 93. Some features of the observed local wind climate provide the experimental background for this study and will be presented in section 3 . Finally, in section 4 we will apply a diagnostic katabatic wind model to East Antarctica, in an attempt to explain the present distribution of BIAs in this part of the continent. In the next section, two possible formation mechanisms for BIAs are discussed.

\section{BLUE-ICE AREAS: FORMATION AND STABILITY}

In contrast to most of the surface of the Antarctic ice sheet, BIAs have a negative mass balance (Fujii and 
Kusunoki, 1982; Jonsson, 1992) and introduce a large mass-balance gradient where they are formed. Although they only cover a small fraction of the Antarctic continent, they have received considerable interest in the past few years. It is proposed that a systematic decrease of BIA extent could indicate increased precipitation, which is probably the main effect of a warmer climate on the Antarctic mass balance. Moreover, thousands of meteorites have been found in BIAs in different parts of East Antarctica, mainly in the Transantarctic Mountains and on BIAs in Dronning Maud Land Cassidy and others, 1992). The surface of BIAs, where the snow cover has been removed, is darker than the adjacent snow-covered surface, so the evolution of their spatial extent can be studied using satellite images (Orheim and Lucchitta, 1990). They occur downwind of mountain ridges (nunataks) but also in large areas where no nearby mountains block the ice flow, for instance near Mizuho Station (Takahashi and others, 1988). Crevassed areas also frequently show patches of blue ice. The occurrence of BIAs and their stability indicate that an extreme microclimate must exist, enhanced by local feedback mechanisms. The stability of existing BIAs to local climate variables has been discussed by Bintanja and Van den Broeke (1995). In the present paper, we will discuss parameters that are important for the actual formation of BIAs. First, we will discuss the two mass-balance components that remove mass from an Antarctic snow surface, i.e. possible mechanisms for BIA formation.

\subsection{Spatial variation of sublimation}

Measurements of sublimation over snow in Antarctica are sparse. King and Anderson (1994) found values for the latent-heat flux of -5 to $+5 \mathrm{~W} \mathrm{~m}^{-2}$ at Halley during the Antarctic winter. At D-47 $(1560 \mathrm{ma}$ a.s.l., mean wind speed $12.8 \mathrm{~m} \mathrm{~s}^{-1}$ ), Wendler and others (1988) found a value of $10 \mathrm{~W} \mathrm{~m}^{-2}$ sublimation during the summer in a strong katabatic wind zone. At a comparable spot, Ohata and others (1985) measured a negligible latent-heat flux during winter and a sublimation of $8 \mathrm{Wm}^{-2}$ during summer at Mizuho Station $(2230 \mathrm{~m}$ a.s.l., mean wind speed $10 \mathrm{~m} \mathrm{~s}^{-1}$ ). Closer to the coast, Heinemann and Rose (1990) calculated the latent-heat flux as a rest term that was very small. At Mawson (150 ma.s.l., mean wind speed $8.6 \mathrm{~ms}^{-1}$ ), Wendler and Weller (1989) found a higher value of $26 \mathrm{~W} \mathrm{~m}^{-2}$ during summer. Over bare ice, sublimation rates are significantly higher (see section 2.3). Over snow, it seems safe to assume that yearly integrated sublimation in Antarctica is generally small, even during high wind-speed conditions. Spatial variations in sublimation are therefore unlikely to initiate BIA formation.

\subsection{Divergence of wind-driven snow}

Another mechanism that can possibly account for BIA formation is divergence of wind-driven snow transport. Drifting snow has been studied quite extensively in the past (Budd, 1966; Loewe, 1970; Kobayashi, 1978; Schmidt, 1986; Wendler, 1989; Giovinetto and others, 1992 and its importance for the surface mass balance of Antarctica is widely accepted. Fluxes of drifting snow are presented as the amount of mass that is transported through a cross-section of the air during a certain time interval, expressed in $\mathrm{kg} \mathrm{m}^{-1}$ year ${ }^{-1}$. Typical values of estimated yearly rates of drifting-snow transport in the escarpment region are $3 \times 10^{6} \mathrm{~kg} \mathrm{~m}^{-1}$ year ${ }^{-1}$ at Mizuho Station (2200ma.s.l.; Kobayashi, 1978) to $6 \times 10^{6} \mathrm{~kg}$ $\mathrm{m}^{-1}$ year $^{-1}$ at D-47 (1560 m a.s.l.; Wendler, 1989) and lower for most higher-situated stations. According to estimates from Loewe (1970), values of up to 10 times larger can be found in even more windy areas. These figures also indicate that if, for whatever reason, a systematic divergence in snowdrift transport occurs of only $5 \%$ over, let us say, $1 \mathrm{~km}$ downwind, $150-300 \mathrm{~kg}$ of snow will be removed per $\mathrm{m}^{2}$ ! This results in a yearly erosion of $15-30 \mathrm{~cm}$ water equivalent each year (w.e. year $^{-1}$, a figure that exceeds the yearly amount of precipitation/deposition at most stations at this elevation.

Moreover, the nature of drifting/blowing snow makes it particularly sensitive for local topographic variations. First, because it is a surface-bounded phenomenon: variations in surface topography strongly influence its spatial distribution. Secondly, the amount of drifting snow depends to a first order on surface-wind speed but this relation is strongly non-linear. This indicates that small temporal variations in wind speed will cause very large variations in drifting-snow flux. Since accumulation increases sharply when descending towards the coast (Fortuin and Oerlemans, 1990) and the winds in the interior of the continent are much more gentle (Wendler and Kodama, 1985; Parish and Bromwich, 1991), the most likely region for BIAs to be formed by divergence of winddriven snow flux is the escarpment region, where strong winds and relatively low accumulation rates prevail.

\subsection{Feed-back mechanisms}

Several feed-back mechanisms ensure that, once BIAs have formed, they tend to persist. This should be borne in mind when using present-day observations in explaining BIA formation. Probably the most important positive feed-back is the smoothness of the ice surface, causing wind to be generally stronger over ice than over snow. Snowpatches on the blue ice will therefore experience relatively large drag, resulting in high values of friction velocity, promoting the upward lift of the snow particles and the disintegration of these snowpatches.

Another widely accepted feed-back mechanism that maintains the local mass-balance gradient is the lower surface albedo of blue ice $(\alpha=0.56)$, compared to its snow surroundings $(\alpha=0.8)$. Available data over blue or bare ice show large ranges from 6 to $37 \mathrm{~cm}$ w.e. sublimation per year (Fujii and Kusunoki, 1982; Clow and others, 1988; Jonsson, 1992). The extra amount of solar heat that is absorbed at the blue-ice surface enhances sublimation of the ice surface but a large part of it is also used to heat the inner ice layers (Bintanja and Van den Broeke, in press). The amount of sublimation during a 6 week period in the summer reached $3.5 \mathrm{~cm}$ w.e. over the blue ice and a smaller amount over nearby snow. It was observed that sublimation was the only active process determining the surface mass balance of the blue ice, whereas precipitation and erosion also influenced the mass balance over snow.

It must be added, finally, that the importance of the 
above-mentioned feed-back mechanisms in maintaining the extent of a BIA is still questionable. As stated above, sublimation differences over blue ice and snow are relatively small. This is due mainly to the fact that BIAs in the lee side of mountains experience less wind during fair weather conditions, and the smooth ice surface generates less turbulence. Furthermore, it has been observed (personal communication from P. Huybrechts, 1993 that a blue-ice area was completely covered with $2030 \mathrm{~cm}$ of snow during a heavy precipitation event, temporarily eliminating the above-mentioned feed-backs. Several days later, the snow had disappeared and the blue ice had surfaced again.

\section{OBSERVATIONS}

In order to investigate the local climate of an Antarctic BIA, a summer meteorological experiment was performed on the lee side of nunataks where a BIA had formed. The period of measurements was 31 December 1992-10
February 1993. More details of the experiment have been presented by Bintanja and others (1993). The topographic depression that encloses the BIA is caused by the removal of the firn layer and is called Scharffenbergbotnen. The basin is part of Heimefrontfjella, a chain of mountains in Dronning Maud Land, East Antarctica (Fig. 1). Wind speed, wind direction, temperature, humidity and radiation were measured at seven meteorological masts situated inside and outside the basin. A more detailed description of the local energy balance and wind field has been presented by Bintanja and Van den Brocke (in press) and Van den Broeke and Bintanja in press). Here we will briefly discuss the most important results concerning the wind field using observations made at sites 2, 3, 4 and 5 .

During the experiment, two circulation patterns inside the basin could be distinguished, occurring about equally frequently: flow type 1 represents strong easterly winds associated with drifting snow and was caused by migrating cyclones along the coast. Flow type 2 represents weak variable winds, associated with high-
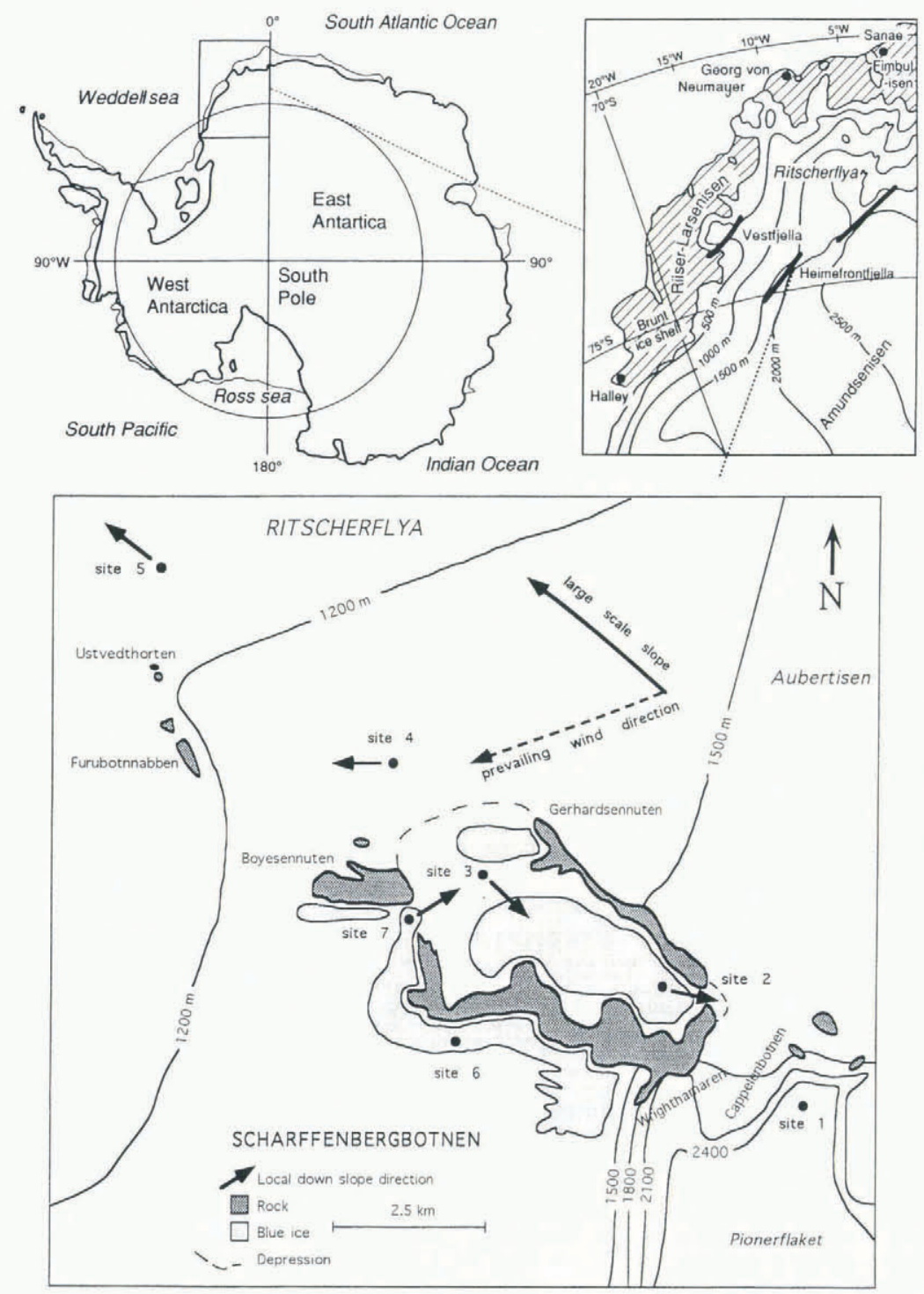

Fig. 1. Location of the experiment in east Dronning Maud Land, Antarctica. In the lower panel, Ihe local slope direction is indicated by solid arrows. 
pressure build-up in the Weddell Sea (King, 1989). Drifting and blowing snow were observed only during flow type 1. Daily mean wind speed at sites 2 (inside the basin, over the blue ice) and 5 (outside the basin, over snow) is plotted in Figure 2. A notable phenomenon is that wind speeds measured over the BIA are greater than outside the basin during type 1 flow (as approximately indicated by the line of $6 \mathrm{~m} \mathrm{~s}^{-1}$ ). Wind speeds at site 3 , where a deep snow ridge has formed, are generally much lower than at either of these locations. In order to explain these differences, which are important for the local driftingsnow distribution, we will first correct the measured surface winds for surface roughness and stability.

The wind-speed profile in the atmospheric surface layer depends on the local aerodynamic surface roughness and stability according to:

$$
V(z)=\frac{u^{*}}{\kappa}\left[\ln \left(\frac{z}{z_{0}}\right)+\psi_{\mathrm{M}}\left(\frac{z}{L}\right)\right]
$$

where $V$ is wind speed, $u^{*}$ is the friction velocity, $z_{0}$ is the aerodynamic surface-roughness length and $\psi_{\mathrm{M}}(z / L)$ is the stability correction, being a function of the Monin Obukhov length $L$. Only hourly mean observations that satisfied the condition $u^{*}>0.1 \mathrm{~m} \mathrm{~s}^{-1}$ at all four sites, and furthermore expressions for dimensionless wind shear as proposed by Duynkerke (1991), are used. For an estimate of the surface-layer depth, the gradient Richardson number $\mathrm{Ri}_{g}$ is defined as

$$
\operatorname{Ri}_{g}=\frac{g \Delta \overline{\theta_{\nu}} \Delta z}{\overline{\theta_{\nu}}\left[(\Delta \bar{u})^{2}+(\Delta \nu)^{2}\right]}
$$

where $\theta_{\nu}$ is virtual potential temperature, $z$ is height above the surface, and $u$ and $\nu$ are the wind components. Average values of surface characteristics are given in Table 1 , based on measurements made at 2 and $6 \mathrm{~m}$. Small values of $\mathrm{Ri}_{g}$ in Table 1 indicate that at sites 2 and
Table 1. Average surface characteristics at sites 2, 3, 4 and 5 for hourly mean values with $u^{*}>0.1 \mathrm{~ms}^{-1}$ at all four sites from 198 hourly averages. $z_{0}$ values are taken from Bintanja and Van den Broeke (in press)

\begin{tabular}{lcccl}
\hline & Sile 2 & Site 3 & Site 4 & Site 5 \\
& & & & \\
\hline $\mathrm{Ri}_{g}$ & +0.030 & +0.115 & +0.024 & -0.005 \\
$V_{6 \mathrm{~m}}\left(\mathrm{~m} \mathrm{~s}^{-1}\right)$ & 9.7 & 7.8 & 9.5 & 9.1 \\
$u^{*}\left(\mathrm{~m} \mathrm{~s}^{-1}\right)$ & 0.27 & 0.23 & 0.40 & 0.40 \\
$z_{0}\left(\mathrm{~mm}^{-1}\right)$ & 0.007 & 0.084 & 0.55 & 0.75 \\
$\Psi_{\mathrm{m}}\left(z L^{-1}\right)$ & 0.54 & 2.19 & 0.23 & 0.18 \\
\hline
\end{tabular}

4 the mean profile is near neutral and even slightly statically unstable at site 5. However, at site 3 the stratification is significantly more stable, which is a direct consequence of the lower surface-wind speed. The height to which we can apply Equation (1), as suggested by Yamada (1976), is the depth of the turbulent layer in stable conditions and the height of the inversion during unstable conditions. Only six balloon soundings could be made inside the basin during flow type 1, owing to high mean wind speeds throughout the boundary layer. The lowest $200 \mathrm{~m}$ of the mean vertical profile for these soundings is given in Figure $3 \mathrm{a}-\mathrm{d}$. A layer of strong wind shear can be detected in the lowest $80 \mathrm{~m}$, associated with $\mathrm{Ri}_{g}<1$, identifying a turbulent surface layer in a weakly statically stable environment. The inversion of temperature and specific humidity tend to be somewhat higher at approximately $150 \mathrm{~m}$. Bearing in mind that, on average, wind speed during snowdrift (flow type 1) will be generally higher than suggested by these balloon data, applying Equation (1) to $80 \mathrm{~m}$, seems justified.

The resulting mean wind-speed profile in the surface layer during drifting-snow conditions, based on surface

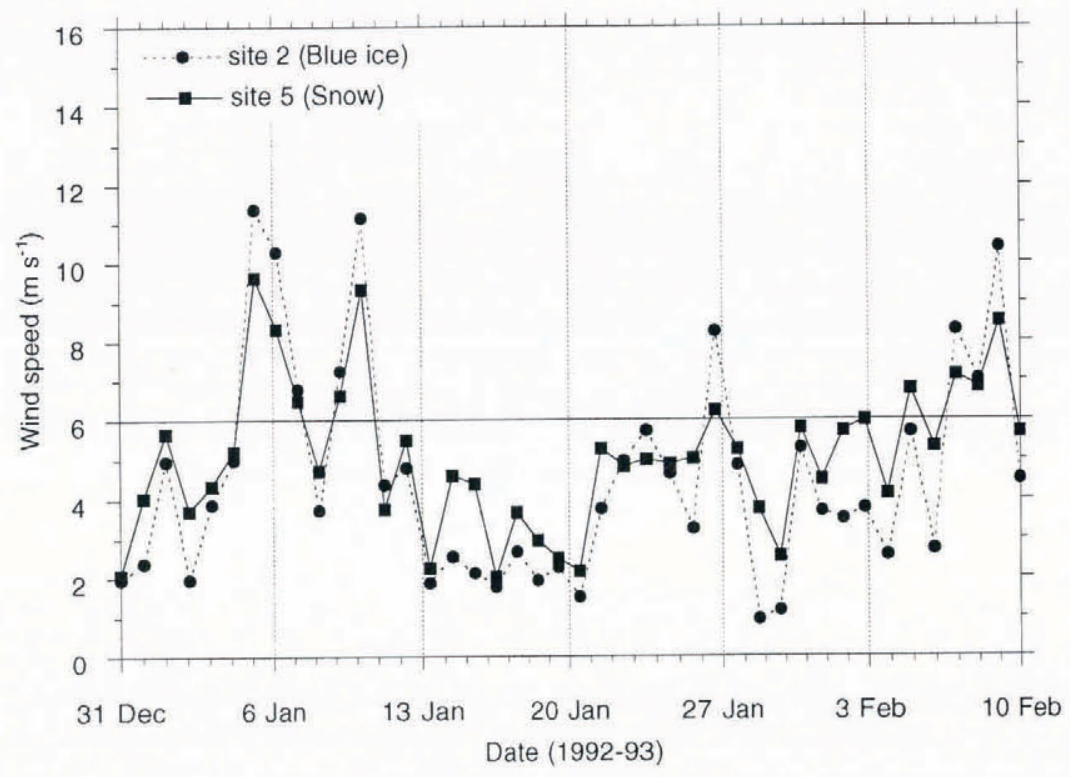

Fig. 2. Daily mean values of $6 \mathrm{~m}$ wind speed at site 2 (inside the valley) and site 5 (outside the valley) for the period 31 December 1992-10 February 1993. 

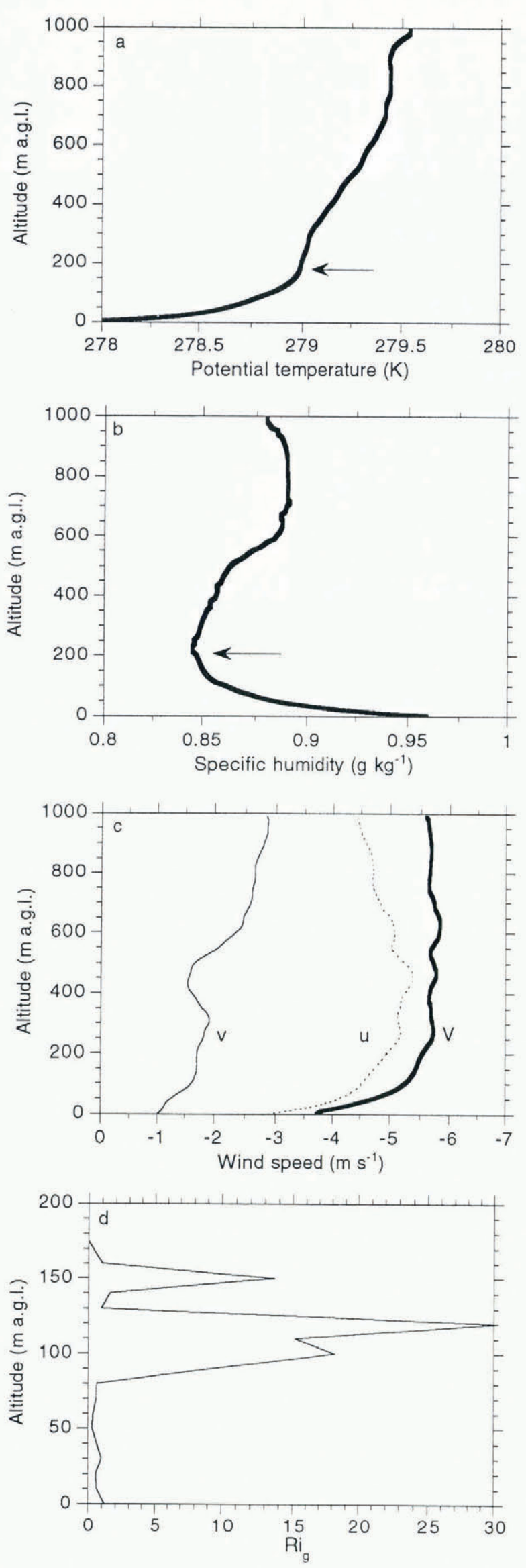

Fig. 3. Mean vertical profiles of potential temperature (a), specific humidity (b), wind speed (c) and components and gradient Richardson number $\mathrm{Ri}_{g}(d)$ (note different vertical scale in the lowest panel). ma.g.l. stands for "metres above ground level". measurements, is shown in Figure 4. For the selected observations, the observed wind speed over the smooth blue ice (site 2) converges towards the same value in the upper-surface layer as wind speeds measured outside of the basin (sites 4 and 5). Since conditions are near-neutral for sites 2, 4 and 5, we can conclude that the observed acceleration of the wind over the blue ice (Fig. 2) can be fully attributed to the smoother surface of the blue ice, as had been proposed earlier by Fujii and Kusunoki (1982). This proves, at least qualitatively, that during driftingsnow conditions the boundary layer is well mixed and the presence of a nunatak upwind does not decrease surfacewind speed significantly. This is an important conclusion, since it indicates that we can use a diagnostic wind-speed model to predict wind speeds even behind barriers that (partly) prevent drifting snow from passing.

The wind-speed profile at site 3 (Fig. 4) converges towards a much lower value. If the mean profile of site 5 is assumed to resemble conditions upwind of the nunataks, the difference in surface-wind speed between sites 3 and 5 could explain snowdrift convergence at site 3 (resulting in the presence of a snow ridge), if shielding ability of the upwind mountain is insufficient. This is visually confirmed by the presence of a depression in the upwind mountains through which snow can freely drift into the basin where is it deposited. The reason for the lower wind speed at site 3 is not clear at present but it is probably associated with the presence of a high, isolated obstacle downwind of this site (Boyesennuten; Fig. 1), forcing the boundary-layer air to diverge and consequently to decelerate.

\section{APPLICATION OF A DIAGNOSTIC KATABATIC WIND MODEL}

The observations suggest that surface winds behind barriers during drifting-snow conditions do not have to be corrected for the presence of this barrier, while the shielding effect of the barrier on drifting-snow transport can be prescribed. Takahashi and others (1988) linked divergence of the surface-wind field to the occurrence of BIAs on Mizuho Plateau, where no nunataks obstruct the drifting-snow transport. Their approach, based on the theoretical model proposed by Ball (1960), will be followed and extended to the situation that includes the shielding effect of nunataks on drifting-snow transport. We consider stationary flow, without the influence of upper-air movement and advection, as a first approximation for yearly averaged surface winds. The driving force is negative bouyancy caused by the cooling of air over sloping terrain (the katabatic force) and it is balanced by frictional and Coriolis forces. The $x$ axis is aligned along the downslope direction:

$$
\begin{aligned}
& 0=-k V u+f \nu+g \frac{\Delta \theta}{\theta_{0}} \sin (\alpha) \\
& 0=-k V \nu-f u
\end{aligned}
$$

where $k$ is a constant friction coefficient $\left(1.25 \times 10^{-5} \mathrm{~m}^{-1}\right.$, based on measurements at Mizuho Station), representing a drag coefficient divided by the boundary-layer depth, $V$ is the absolute wind speed, $f$ is the Coriolis parameter, $\Delta \theta$ 


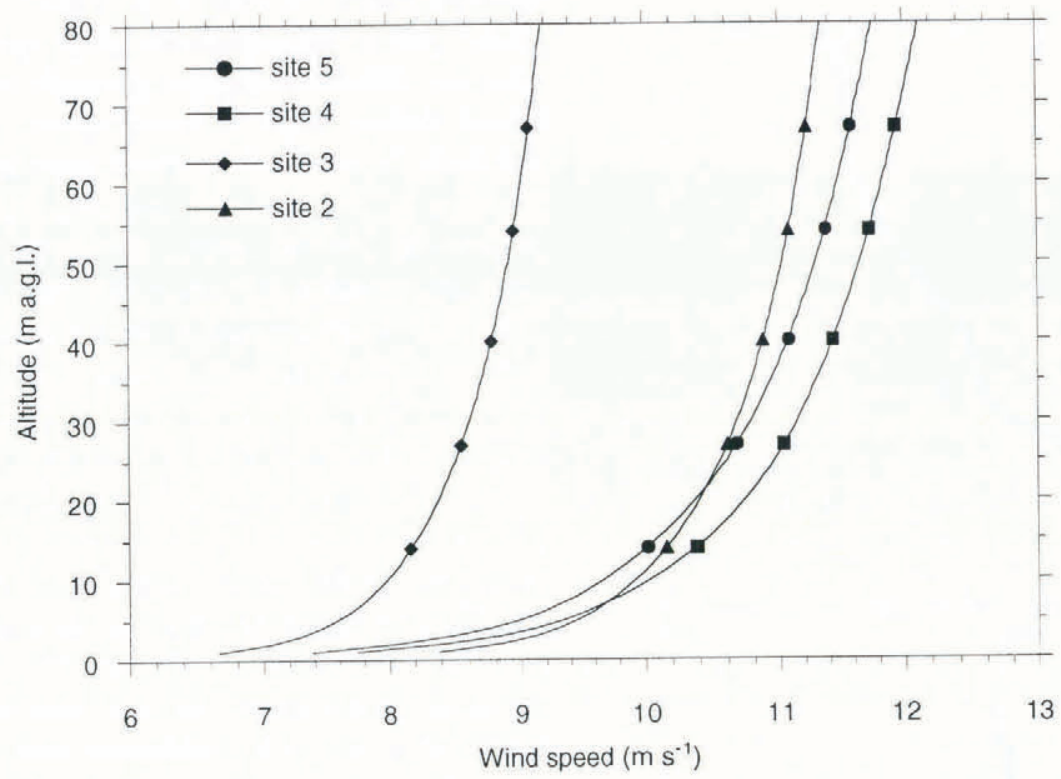

Fig. 4. Surface-layer profiles of wind speeds at sites 5, 4, 3 and 2, calculated according to Equation (1) and the mean variables in Table 1. ma.g.l. stands for "metres above ground level".

is the inversion strength, $\theta_{0}$ is the mean background temperature and $\alpha$ is the surface-slope angle. Solving for wind speed and wind direction, we obtain:

$$
\begin{aligned}
V & =\left[\frac{\cos (\delta)}{k} g \frac{\Delta \theta}{\theta_{0}} \sin (\alpha)\right]^{\frac{1}{2}} \\
\cos (\delta) & =\frac{-f^{2}}{2 k \frac{\Delta \theta}{\theta_{0}} \sin (\alpha)}+\left[\left(\frac{f^{2}}{2 k \frac{\Delta \theta}{\theta_{0}} \sin (\alpha)}\right)^{2}+1\right]^{\frac{1}{2}}
\end{aligned}
$$

where $\delta$ indicates the angle between the down-pointing surface-slope vector and the surface-wind direction.

\subsection{Application to a two-dimensional topographic profile}

In order to test the model, we chose an idealized twodimensional ice-sheet profile (Fig. 5a), typical for East Antarctic slopes (all empirical expressions are listed in the Appendix). The surface-temperature inversion along Antarctic slopes is mainly a build-up as a result of a strongly negative (longwave) radiation balance at the surface that is balanced by a downward-directed transport of sensible heat. Increase of the katabatic wind then implies mixing of the surface layer with the warm upper-layer air that decreases the inversion strength until a balance is established. To parameterize this continuous balance, it was chosen to express the inversion strength not only as a function of altitude but also of slope magnitude (see the Appendix). This parameterization predicts a larger inversion over the coastal ice shelves than over the steep coastal slopes (Fig. 5b), which is confirmed by observations (Phillpot and Zillman, 1970). Parameterization of surface temperature (Fig. 4b) has been taken from the statistical study of Fortuin and Oerlemans (1990).

The observations that have been inserted here are from an array of automatic weather stations in Terre Adélie, East Antarctica, taken from Wendler and Kodama (1985), and they broadly confirm the applicability of the present diagnostic model. The calculated surface-wind field (Fig. 5c) has the main characteristics of Antarctic katabatic winds. The wind speed increases towards the coast and reaches a maximum just before the ice edge. As the balance between buoyancy forcing, friction and Coriolis force changes, the wind becomes directed more downslope, typical for katabatic winds observed over the large ice sheets of Antarctica and Greenland Parish and Waight, 1987; Van den Broeke and others, 1994).

Several expressions have been developed to link the transport of drifting snow $Q$ to $10 \mathrm{~m}$ wind speed. We use the formula developed by Budd (1966). The yearly net removal/deposition of snow from the surface is represented by the divergence/convergence of the snow transport, that equals $\partial Q / \partial x$ in the two-dimensional configuration (Fig. 6). The yearly transport rate along this idealized profile reaches $7 \times 10^{6} \mathrm{~kg} \mathrm{~m}^{-1}$ year ${ }^{-1}$ as a maximum value. Although the absolute magnitude of the transport is large, the divergence is quite small, reaching at most $10 \mathrm{cmw}$.e. year ${ }^{-1}$ (dashed curve in Figure 6). Closer to the coast, on the ice shelves, the mass transport decreases in response to lower wind speeds. This results in a deposition of up to $10 \mathrm{~cm}$ w.e. year ${ }^{-1}$. Although significant, the erosion is too small to exceed precipitation minus sublimation near the coast, which typically lies in the range of $30-60 \mathrm{~cm}$ w.e. year ${ }^{-1}$. This means that an additional decrease in upwind drifting-snow transport is needed to explain the occurrence of areas with negative surface mass balance. In reality, these upwind decreases are, for example, provided by nunataks or crevasses that prevent drifting snow from passing, or sublimation of drifting snow into the air.

In order to test the sensitivity of the steady-state snow transport of Figure 6 to the formation of BIAs, we will 

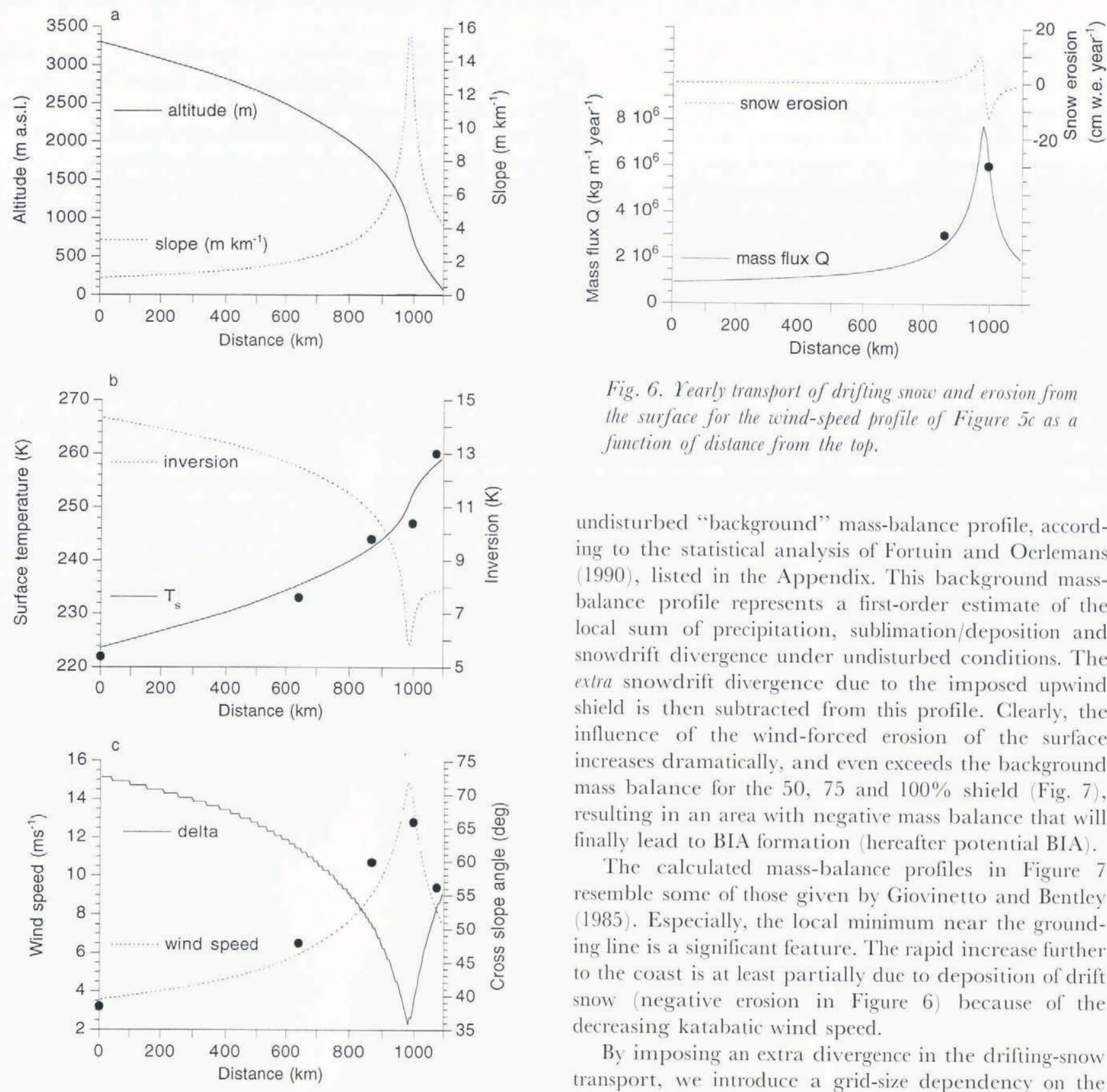

Fig. 6. Tearly transport of drifting snow and erosion from the surface for the wind-speed profile of Figure $5 \mathrm{c}$ as a function of distance from the top.

undisturbed "background" mass-balance profile, according to the statistical analysis of Fortuin and Oerlemans (1990), listed in the Appendix. This background massbalance profile represents a first-order estimate of the local sum of precipitation, sublimation/deposition and snowdrift divergence under undisturbed conditions. The extra snowdrift divergence due to the imposed upwind shield is then subtracted from this profile. Clearly, the influence of the wind-forced erosion of the surface increases dramatically, and even exceeds the background mass balance for the 50, 75 and 100\% shield (Fig. 7), resulting in an area with negative mass balance that will finally lead to BIA formation (hereafter potential BIA).

The calculated mass-balance profiles in Figure 7 resemble some of those given by Giovinetto and Bentley (1985). Especially, the local minimum near the grounding line is a significant feature. The rapid increase further to the coast is at least partially due to deposition of drift snow (negative erosion in Figure 6) because of the decreasing katabatic wind speed.

By imposing an extra divergence in the drifting-snow transport, we introduce a grid-size dependency on the

Fig. 5. Output of diagnostic model for horizontal profiles of elevation and slope angle (a), surface lemperature and inversion strength $(b)$, wind speed and deviation from the fall line (c) as a function of distance from the top.

impose the condition that a certain fraction of the snow suspended at the upwind grid point is shielded from migrating to the downwind grid point, i.e. we shall impose an extra divergence on the snowdrift transport in the downslope direction at each grid point. This approach is justified by the observations that the wind field is not affected by the presence of a nunatak during drifting-snow conditions. The deposited snow is assumed to accumulate locally, where eventually it will be incorporated into the larger-scale ice flow. The results for a 25, 50, 75 and 100\% effective shield are given in Figure 7. The present calculations are done for a gridpoint distance of $5 \mathrm{~km}$, so that the divergence (using centred differences) applies to a horizontal stretch of $10 \mathrm{~km}$ along the horizontal. The solid line represents an

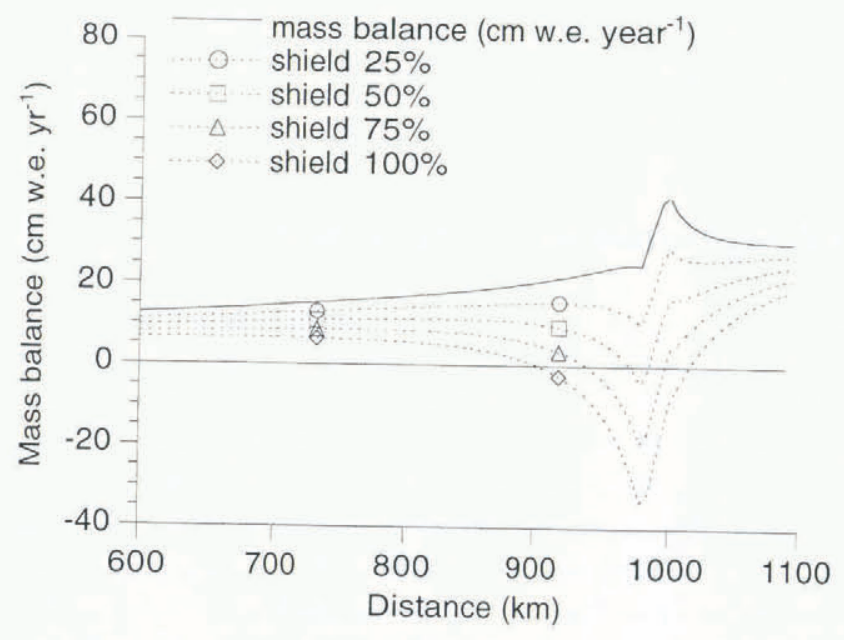

Fig. 7. Background surface mass-balance profile (solid line) and perturbed mass-balance profiles for 25, 50, 75 and $100 \%$ shielding of drifting snow from the upwind grid point as a function of distance from the top. 
results. Using the simple wind-speed-snowdrift rate relation given in the Appendix, the local mass balance for a $100 \%$ shield solely depends on the wind speed (i.e. export of drift snow), the local background mass balance (i.e. import/export of snow by precipitation/sublimation) and the size of the area affected by the upwind shield. The yearly averaged wind speed needed to export the background mass balance as a function of area size (i.e. to make the total mass balance zero, or the threshold situation for BIA formation) is given in Figure 8. For instance, for a typical BIA size of $10 \mathrm{~km}$ along the wind vector (grid size $\Delta x$ ), in an area where the background mass balance equals $25 \mathrm{~cm}$ w.e. year ${ }^{-1}$, an average yearly wind speed in the order of $8 \mathrm{~ms}^{-1}$ can initiate BIA formation provided no mass is being imported into the region other than the background mass balance (100\% shield). Of course, the present calculations are only an order-of-magnitude estimate. Several assumptions are difficult to verify, such as availability of snow for drifting, hardening of snow, etc.

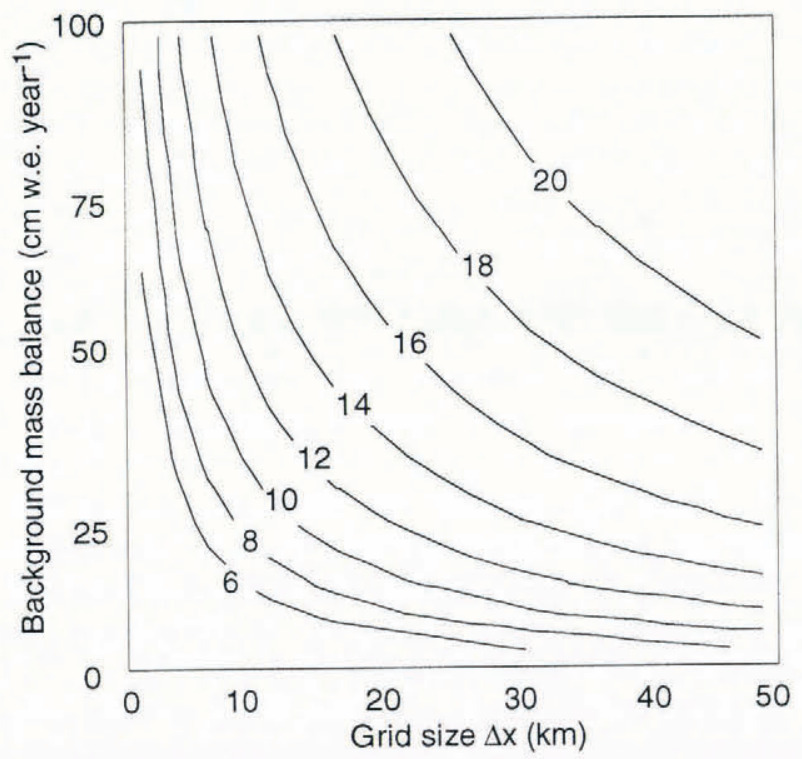

Fig. 8. Tearly mean wind speed needed to remove the background mass balance ( $y$ axis) from an area with length $\Delta x$ ( $x$ axis), according to the present parameterization.

\subsection{Application to East Antarctica}

We will now apply the model to the topography of entire East Antarctica, excluding the Transantarctic Mountains, since their rugged topography does not allow application of the present model. The topographic data set used is the $20 \mathrm{~km} \times 20 \mathrm{~km}$ resolution Scott Polar Research Institute topography (Drewry, 1983). Thus, $\Delta x$ is fixed to $20 \mathrm{~km}$ in the following. All other parameterizations are the same as those mentioned in section 4.1 . Maximum inversion strength was again set at $15 \mathrm{~K}$ and only slopes equal to or less than $20 \mathrm{~m} \mathrm{~km}^{-1}$ were allowed. The applied background mass balance according to Equation (A5) is presented by Figure 9. It shows the large area in the interior with a very low mass balance and the steep mass-balance gradients near the coast, especially in Dronning Maud Land (i.e. the coastal area between $45^{\circ} \mathrm{W}$ and $45^{\circ} \mathrm{E}$ ). The calculated wind speeds are given in Figure 10 and the total yearly amount of drifting snow in Figure 11. A belt of high mean wind speed $\left(>10 \mathrm{~m} \mathrm{~s}^{-1}\right)$ can be recognized following the area of steepest slope angles. These wind speeds are realistic and represent the ordinary katabatic wind regime. The maximum yearly amount of drifting snow is in the range of $10-15 \times 10^{6} \mathrm{~kg} \mathrm{~m}^{-1}$ year ${ }^{-1}$. Clearly, the one-dimensional model is not able to simulate extremely high wind speeds in the coastal areas in Terre Adélie (Port Martin, Cape Denison), which are probably caused by local convergence of the flow by the topography (Parish and Bromwich, 1991).

Analogous to the two-dimensional profile (Fig. 6), the maximum erosion/deposition by snowdrift divergence/convergence is about $10 \mathrm{cmw}$.e. year ${ }^{-1}$ (not shown) in the present analysis, and is evenly distributed along the coastal zone. If we impose a $100 \%$ shield on all grid points, and subtract the extra erosion from the background mass-balance profile (Fig. 12), the resulting mass-balance distribution shows areas with negative values (potential BIAs). Three potential BIAs show up: the dry interior close to the South Pole where wind speeds are high enough to exceed the driftingsnow limit significantly, the basin of Lambert Glacier and the escarpment zone of Dronning Maud Land. Owing to the absence of barriers that allow for shielding of drift snow close to the South Pole (nunataks, crevasses), BIA formation will not be observed here. In the other two areas, however, BIAs are frequently observed in the vicinity of mountains and/or crevasses, including the small BIA where the meteorological experiment described in section 2 was performed. Potential BIA size in Figure 12 represents $18 \%$ of the total surface of this part of East Antarctica. Only a small fraction of this area actually becomes BIA, namely, at those locations where sufficient shielding is available.

\section{SENSITIVITY TO VARIATION OF EXTERNAL PARAMETERS}

When the climate of Antarctica becomes warmer, precipitation is expected to increase and the surfacetemperature inversion will decrease, the latter owing to increased longwave incoming radiation at the surface. Both parameters are directly involved in the above analysis of drifting-snow transport. We investigate the change of potential BIA size as a function of change in these two parameters: a relative increase of background mass balance and a relative decrease of inversion strength (Fig. 13). Clearly, potential BIA size decreases much more rapidly when the inversion strength decreases compared to an equal relative rise in the background mass balance. There are several reasons for this large sensitivity to inversion strength in the present model. The wind speed, which is directly linked to inversion strength, will become weaker and, combined with the logarithmic dependency of drifting-snow transport on wind speed, this will lead to a dramatic 


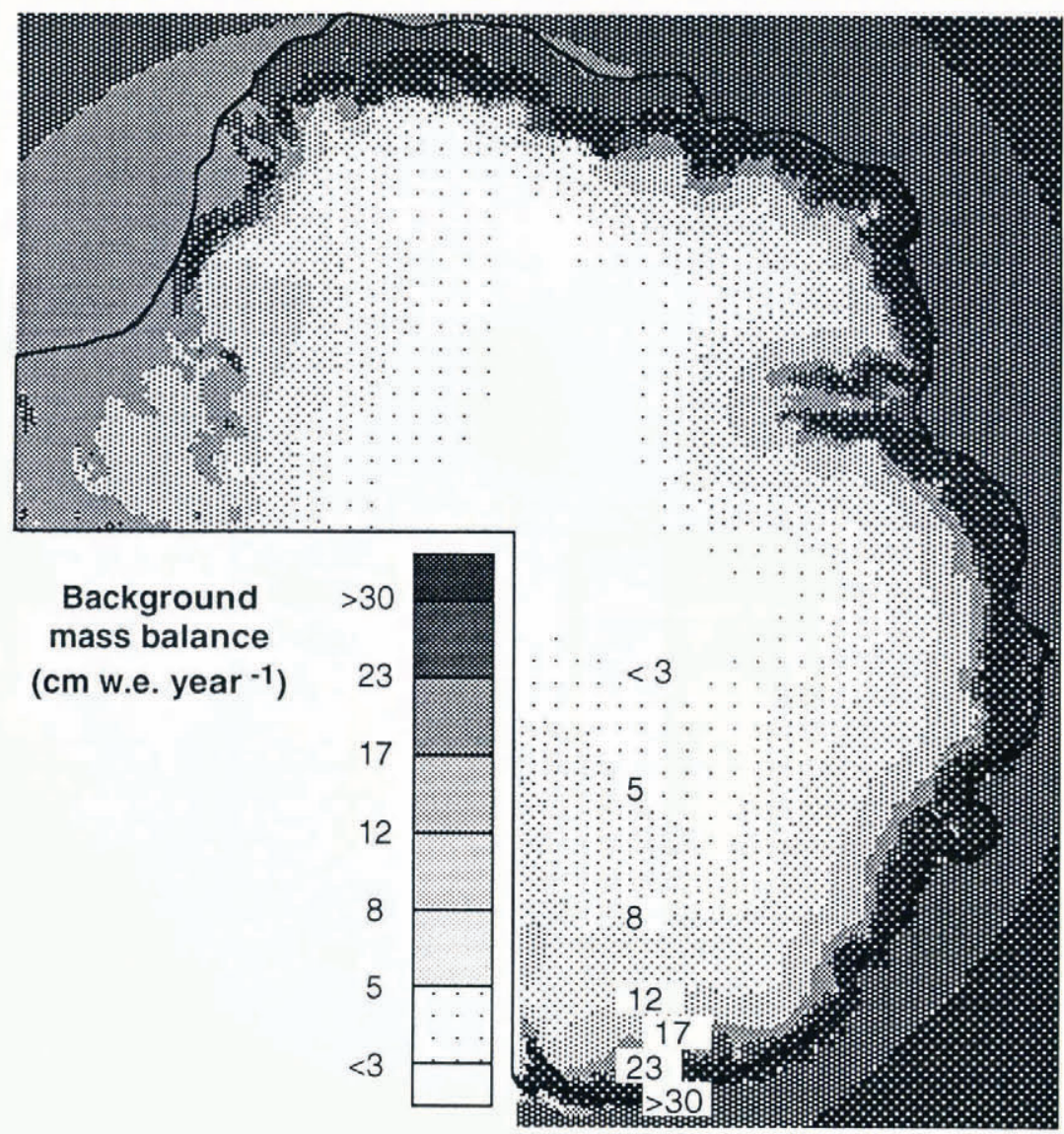

Fig. 9. Background surface mass-balance distribution in $\mathrm{cm}^{\text {w.e.year }}{ }^{-1}$ according to Fortuin and Oerlemans (1990); Equation (A5).

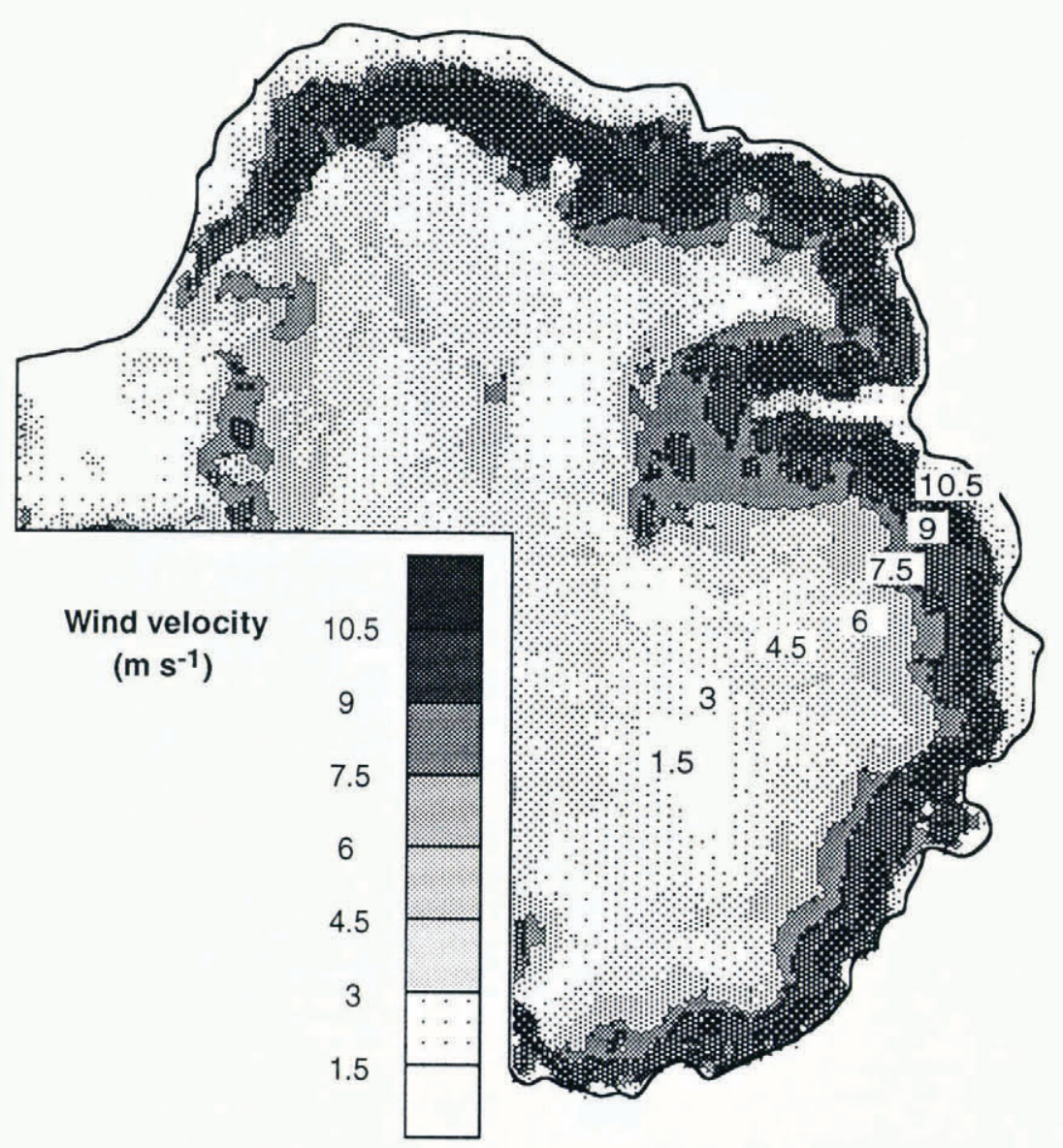

Fig. 10. Steady-state wind velocity according to Equation (6). 


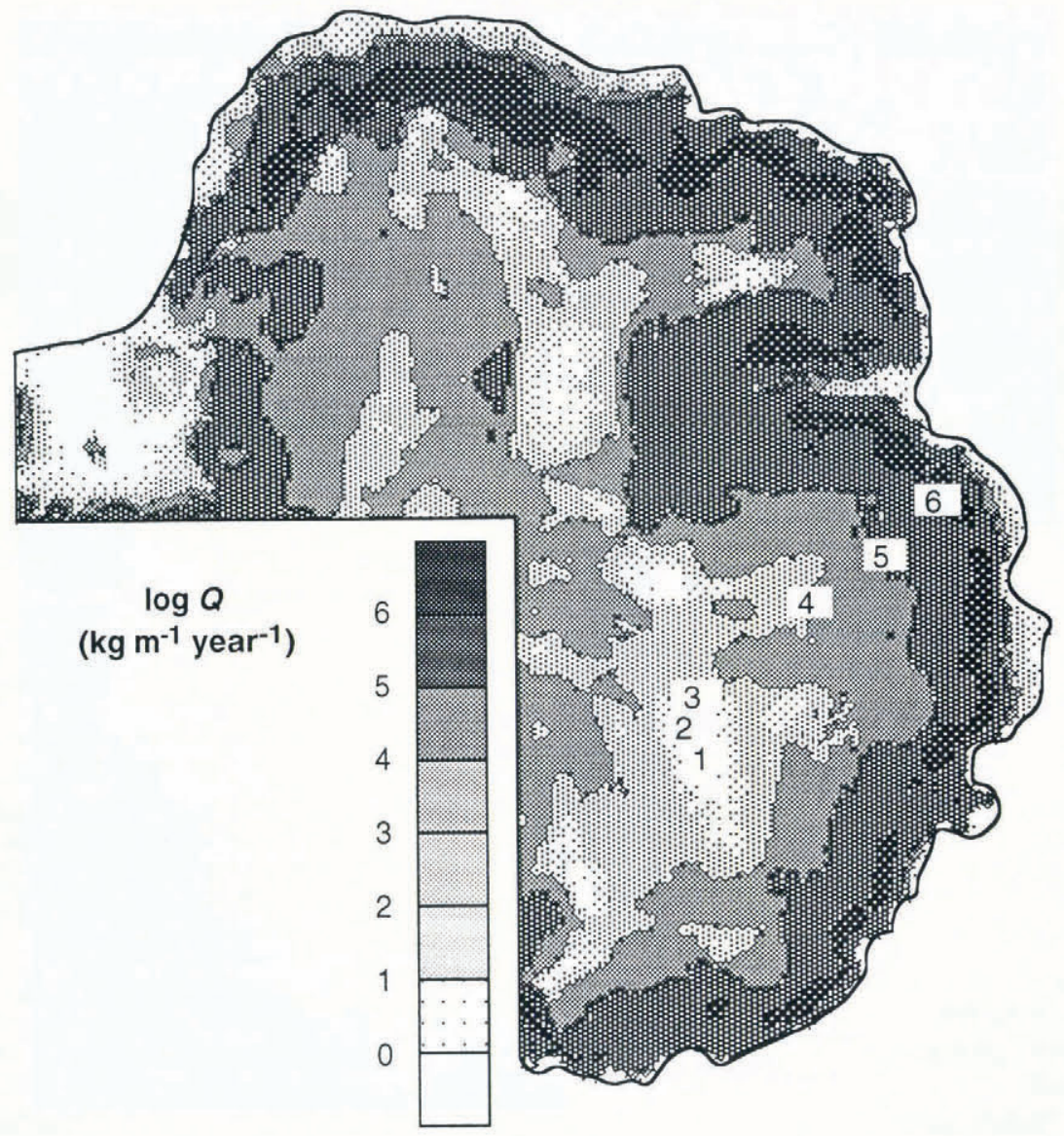

Fig. 11. Logarithm of yearly transport rate of drifling snow according to Equation (A3).

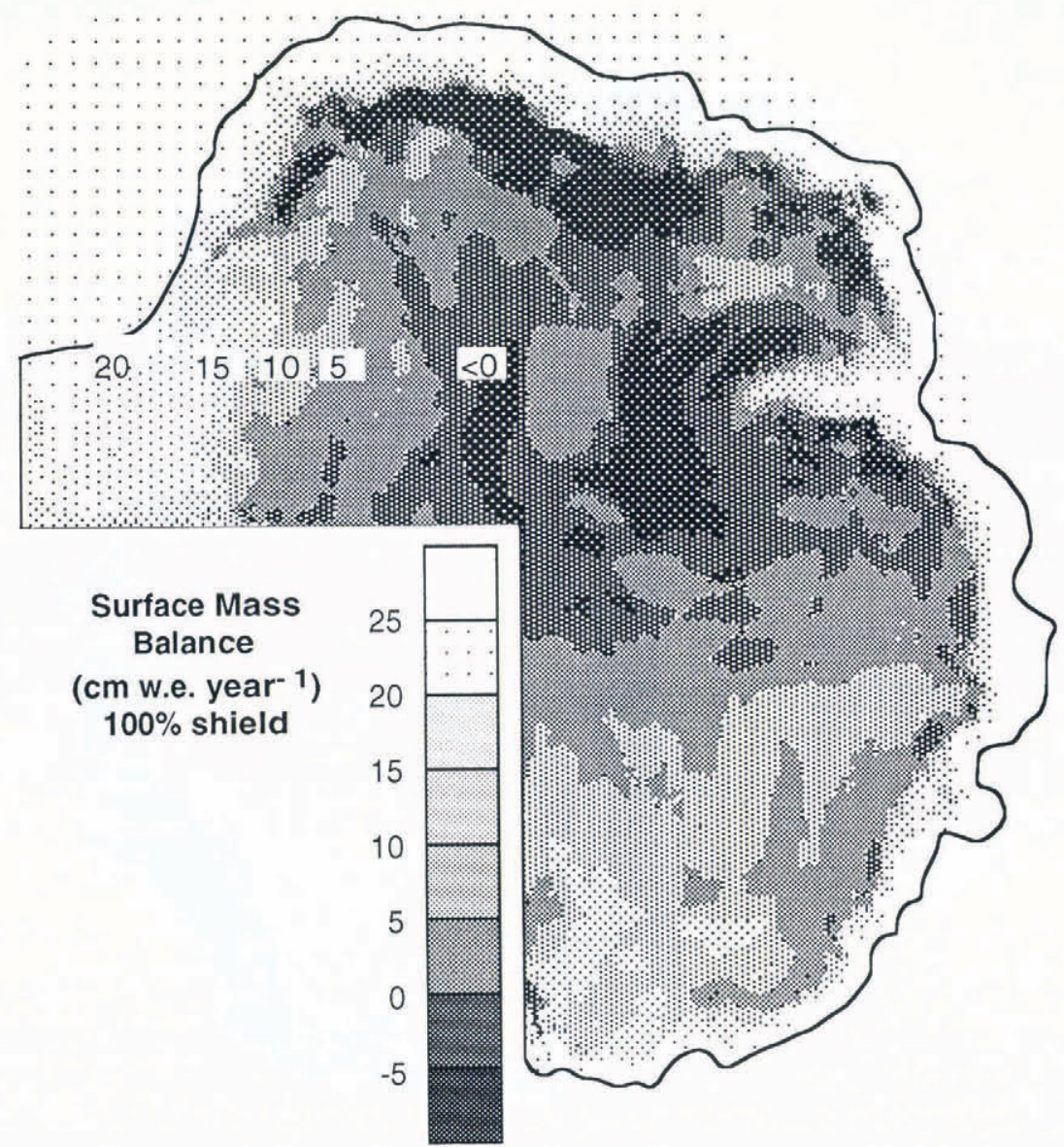

Fig. 12. Resulting surface mass balance when the extra erosion due to a $100 \%$ shield from upwind drifting is subtracted from the background mass balance (Fig. 9). 


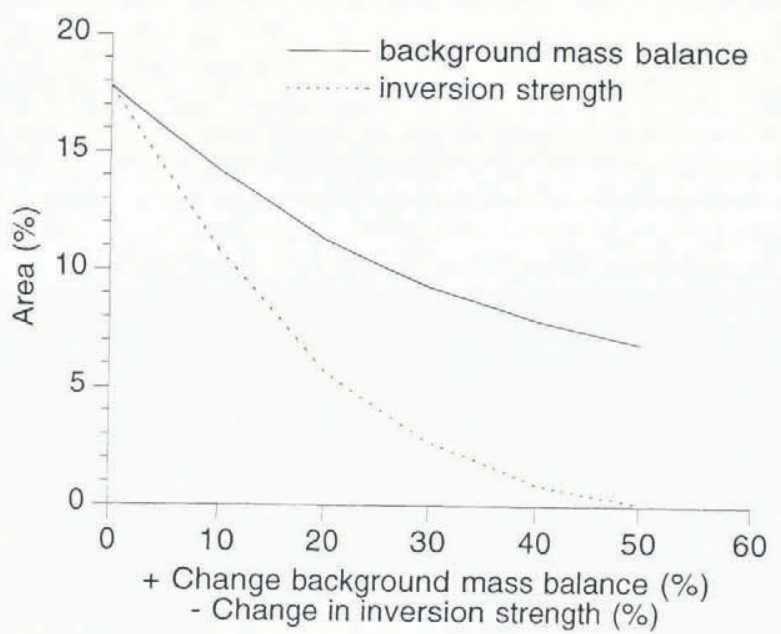

Fig. 13. Potential BIA size, expressed as a percentage of East Antarctica as a function of increase in background mass balance (solid line) or decrease in inversion strength (dotled line).

decrease in drifting-snow transport (divergence). The small sensitivity to an increased background mass balance can be ascribed to the steep mass-balance gradients in the vicinity of BIAs (Fig. 6). This was also concluded by Bintanja and Van den Broeke (1995) by studying the sensitivity of the BIA extent to variation in local energy-balance components. Figure 13 also shows that, according to the present analysis, no potential BIA remains when the surface inversion would decrease by $50 \%$ i.e. maximum inversion strength in Equation (A2) becomes $7.5 \mathrm{~K}$ ). For an increase in the background mass balance of $50 \%$, half of the original potential BIA remains. From this, we may conclude that formation (and therefore also degradation) of BIAs is much more sensitive to a change in surface-inversion strength and the associated decreasing katabatic wind speeds than to an increase in background mass balance by increasing precipitation).

The spatial distribution of potential BIA for a $20 \%$ change in both inversion strength and background mass balance is given in Figure 14. It clearly shows that the potential BIA in Dronning Maud Land and around the Lambert Glacier basin is less sensitive than that in the interior. This can be attributed to the steeper massbalance gradients in the coastal locations, because of the higher wind speeds.

\section{CONCLUSIONS}

The present analysis shows that potential BIAs are characterized by a combination of low accumulation rates (altitude $>1000 \mathrm{ma}$ a.s.l.) and steep slopes (high wind speeds). This combination is only found in the interior close to the South Pole, in Dronning Maud Land and in the Lambert Glacier basin. In the other parts, the wind-speed maximum occurs in warmer places or locations that are too close to the coast, i.e. where the background mass balance is too high (e.g. Terre Adélie). Although the figures given here can only be regarded as order-of-magnitude estimates, they

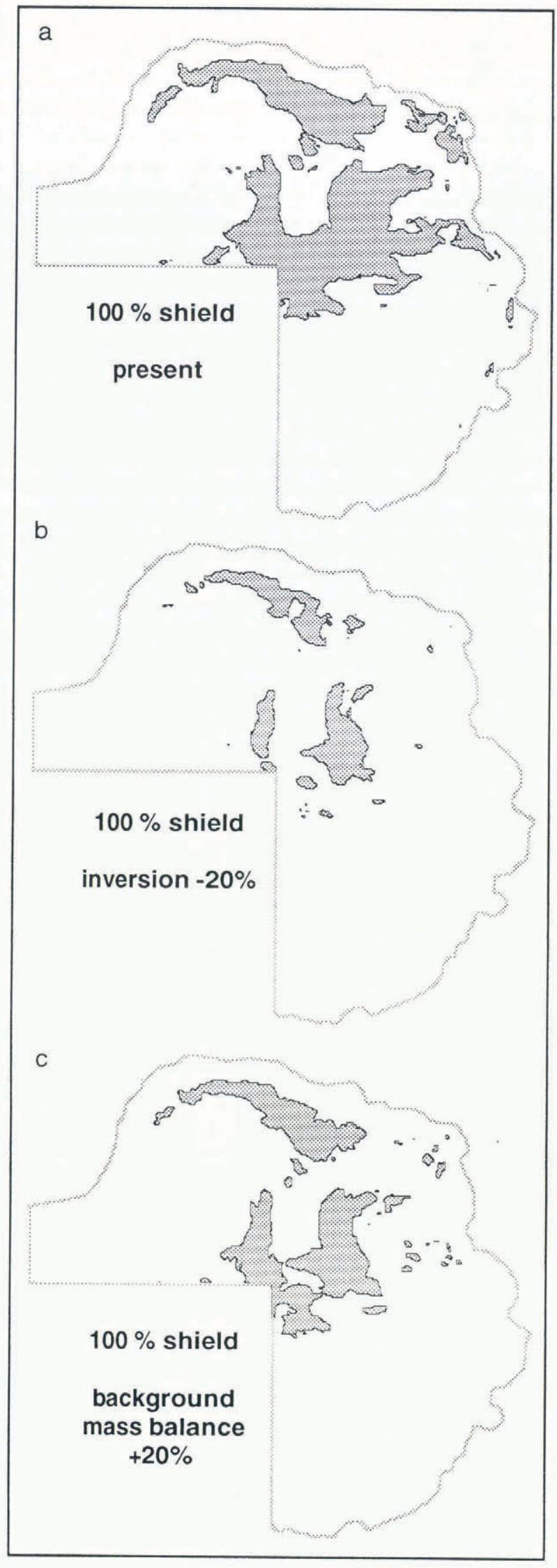

Fig. 14. Potential BIAs (dark stippled areas) for present simulation (a), for situation with 20\% decreased inversion strength (b) and $20 \%$ increased background mass balance $(c)$. 
provide a more quantitative insight into the interaction between katabatic wind, snow erosion and mass balance, based on empirical and simple theoretical considerations. Within the present framework, areas with a negative mass balance in Antarctica can only be explained when an additional divergence of drifting snow is applied. In reality, these decreases in mass transport are represented by crevasses (microscale) and nunataks (mesoscale) or sublimation of drifting snow. Observations show that, in reality, BIAs are either linked to the presence of nunataks and crevasses or in combination with large-scale slope divergence. Feedback mechanisms not accounted for in the present calculations are probably responsible for the windward extension of BIAs into regions where BIA formation would normally not begin.

Because of the strong non-linear relation between drifting-snow transport rate and surface-wind speed, potential BIAs degrade much more rapidly for decreasing wind speeds than for an increase in background mass balance. The potential BIAs along the escarpment, moreover, are less sensitive than those in the interior because of the steeper mass-balance gradient.

Finally, it should be noted that the drifting-snow transport critically depends on the distribution of strong winds. Especially, the very strong wind zones of Terre Adélie, probably caused by the confluence of the cold katabatic air, are not represented by the simple model. The present results should therefore be regarded as estimates rather than specific calculations.

\section{ACKNOWLEDGEMENTS}

The many people involved in the SWEDARP (Swedish Antarctic Research Program) 92/93 expedition are thanked for their support. Valuable comments on the manuscript were given by $\mathrm{H}$. Oerlemans. Funding for this project was provided by the Dutch National Research Programme on Global Air Pollution and Climate Change (NOP) and the Netherlands Antarctic Research Programme $(\mathrm{GOA})$.

\section{REFERENCES}

Ball, F. K. 1960. Wind on the ice slopes of Antarctica. In Antarctic Meteorology. Proceedings of the Symposium held in Melbourne, February 1959. New York, etc., Pergamon Press, 9-16.

Bintanja, R. and M. R. van den Broeke. 1995. The climate sensitivity of Antarctic blue-ice areas. Ann. Glaciol., 21, [][]-[][].

Bintanja, R. and M. R. van den Broeke. In press. The surface energy balance of Antarctic blue ice and snow. F. Appl. Meteorol.

Bintanja, R., M. R. van den Broeke and M.P. Portanger. 1993. A meteorological and glaciological experiment on a blue ice area in the Heimefront Range, Queen Maud Land, Antarctica. Utrecht, Utrecht University. (Svea Field Report. I.M.A.U. Report.)

Broeke, M. R. van den and R. Bintanja. In press. Summer time atmospheric circulation in the vicinity of a blue ice area in east Queen Maud Land, Antarctica. Boundary-Layer Meteorol.

Broeke, M. R. van den, P.G. Duynkerke and J. Oerlemans. 1994. The observed katabatic flow at the edge of the Greenland ice sheet during GIMEX-91. Global and Planetary Change, 9, 3-15.

Budd, W. F. 1966. The drifting of nonuniform snow particles. Antarct. Res. Ser., 9, 59-70.

Cassidy, W. A., R. Harvey, J. Schutt, G. Delisle and K. Yanai. 1992. The meteorite collection sites of Antarctica. Meteoritics, 27 (5), 490-525.

Clow, G. D., C. P. McKay, G. M. Simmons, Jr and R. A. Wharton, Jr.
1988. Climatological observations and predicted sublimation rates at Lake Hoare, Antarctica. 7. Climale, 1, 715-728.

Drewry, D.J., ed. 1983. Antarctica: glaciological and geophysical folio. Cambridge, University of Cambridge. Scott Polar Research Institute.

Duynkerke, P. G. 1991. Radiation fog: a comparison of model simulation with detailed observations. Mon. Weather Rev., 119, 324-341.

Fortuin, J. P.F. and J. Oerlemans. 1990. Parameterization of the annual surface temperature and mass balance of Antarctica. Ann. Glaciol., 14, 78-84.

Fujii, Y. and K. Kusunoki. 1982. The role of sublimation and condensation in the formation of ice sheet surface at Mizuho Station, Antarctica. J. Geophys. Res., 87 (C6), 4293-4300.

Giovinetto, M.B. and C. R. Bentley. 1985. Surface balance in ice drainage systems of Antarctica. Antarct. 7. U.S., 20 4), 6-13.

Giovinetto, M. B., D. H. Bromwich and G. Wendler, 1992. Atmospheric net transport of water vapor and latent heat across $70^{\circ} \mathrm{S}$. J. Geophys. Res., 97(D1), 917-930.

Heinemann, G. and L. Rose. 1990. Surface energy balance, parameterisations of boundary-layer heights and the application of resistance laws near an Antarctic ice shelf front. Boundary-Layer Meteorol., 51, $123-158$

Jonsson, S. 1992. Local climate and mass balance of a blue-ice area in western Dronning Maud Land, Antarctica. Z. Gletscherkd. Glazialgeol., 26 1), 1990, 11-29.

Kind, R.J. 1981. Snow drifting. In Gray, D. M. and D. H. Male, eds. Handbook of snow; principles, processes, management and use. Toronto, Pergamon Press, 338-359.

King, J. C. 1989. Low-level wind profiles at an Antarctic coastal station. Antarct. Sci., 1(2), 169-178.

King, J. C. and P.S. Anderson. 1994. Heat and water vapour fluxes and scalar roughness lengths over an Antarctic ice shelf. Boundary-Layer Meteorol., 69, 101-121.

Kobayashi, S. 1978. Snow transport by katabatic winds in Mizuho Camp area, East Antarctica. J. Meteorol. Soc. Jpn, $\mathbf{5 6}(2), 130$ 139.

Loewe, F. 1970. The transport of snow on ice sheets by the wind. Studies on drifting snow. Melbourne, University of Melbourne. Meteorology Department. (Publication 13.)

Oerlemans, J. 1993. Possible changes in the mass balance of the Greenland and Antarctic ice sheets and their effects on sea level. In Warrick, R. A., E. M. Barrow and T. M. L. Wigley, eds. Climate and sea level change; observations, projections and implications. Cambridge, Cambridge University Press, 144-161.

Ohata, T., N. Ishikawa, S. Kobayashi and S. Kawaguchi. 1985. Heat balance at the snow surface in a katabatic wind zone, East Antarctica. Ann. Glaciol., 6, 174-177.

Orheim, O. and B. K. Lucchitta. 1990. Investigating climate changes by digital analysis of blue ice extent on satellite images of Antarctica. Ann. Glaciol., 14, 211-215.

Parish, T. R. and D. H. Bromwich. 1991. Continental-scale simulation of the Antarctic katabatic wind regime. 7. Climate, 4, 135-146.

Parish, T. R. and K. T. Waight. 1987. The forcing of Antarctic katabatic winds. Mon. Weather Rev., 115, 22142226.

Phillpot, H.R. and J.W. Zillman. 1970. The surface temperature inversion over the Antarctic continent. 7. Geophys. Res., 75 (21), 41614169 .

Schmidt, R.A. 1986. Transport rate of drifting snow and the mean wind speed profile. Boundary-Layer Meteorol., 34 (3), 213241.

Schwerdtfeger, W. 1970. The climate of the Antarctic. In Orvig, S., ed. Climates of the polar regions. Amsterdam, etc., Elsevier, 252-335. (World Survey of Climatology, Vol. 14.

Takahashi, S., R. Naruse, M. Nakawo and S. Mae. 1988. A bare ice field in east Queen Maud Land, Antarctica, caused by horizontal divergence of drifting snow. Ann. Glaciol., 11, 156-160.

Wendler, G. 1989. On the blowing snow in Adélie Land, eastern Antarctica. In Oerlemans, J., ed. Glacier fluctuations and climatic change. Dordrecht, Kluwer Academic Publishers, 261-279.

Wendler, G. and Y. Kodama. 1985. Some results of climatic investigations of Adélie Land, eastern Antarctica. Z. Gletscherkd. Glazialgeol., 21, 319-327.

Wendler, G. and G. Weller. 1989. The summer radiation and heat budget of the Arctic and Antarctic. Theor. Appl. Climatol., 40 (1-2), $53-60$.

Wendler, G., N. Ishikawa and Y. Kodama. 1988. The heat balance of the icy slope of Adélie Land, eastern Antarctica. 7. Appl. Meteorol., 27, 52-65.

Yamada, T. 1976. On the similarity functions A, B and C of the planetary boundary layer. F. Atmos. Sci., 33, 781-793. 


\section{APPENDIX}

\section{EMPIRICAL FORMULAE}

$$
\begin{aligned}
h_{\mathrm{s}} & =45.6(L-x)^{0.31} \quad(\mathrm{~m} \text { a.s.l. }) \\
\Delta \theta & =\Delta \theta_{\max }\left(0.5\left(1-\frac{\alpha}{\alpha_{\max }}\right)+0.5 \frac{h_{s}}{h_{s, \max }}\right) \\
\log (Q) & =1.1812+0.0887 V_{10 \mathrm{~m}} \quad\left(\mathrm{~g} \mathrm{~m}^{-1} \mathrm{~s}^{-1}\right) \\
T_{\mathrm{s}} & =-9.14 h_{\mathrm{s}}-0.688 l a+307.6 \quad(\mathrm{~K}) \\
\mathrm{MB} & =0.62 T_{\mathrm{s}}+0.921 \alpha-20.087 \frac{\partial \alpha}{\partial x}+34.961 \\
(\mathrm{~cm} \text { w.e. year } & -1
\end{aligned}
$$

Equation (A1) represents a typical cross-section of the East Antarctic ice sheet, where $h_{\mathrm{s}}$ is altitude in ma.s.l., $x$ is the distance from the top and $L$ is the length of the trajectory, here set at $1000 \mathrm{~km}$. In order to avoid spurious slope angles, a smooth transition towards sea level was prescribed at the lowest grid points, which can be regarded as an ice shelf attached to the inland ice.

Equation (A2) describes the surface-inversion strength $\Delta \theta$ as a function of slope angle $\alpha$ and altitude $h_{\mathrm{s}}$, where $\Delta \theta_{\max }$ is the yearly averaged inversion strength at the most elevated location (set at $15 \mathrm{~K}$ ) and $\alpha_{\max }$ is the maximum slope angle in the domain. With physical arguments, we can defend the choice for Equation (A2) as follows: with decreasing surface elevation, the temperature of the atmosphere that radiates downward increases, increasing the longwave-radiation balance at the surface and thus decreasing the inversion strength. The choice for the surface slope to determine inversion strength is less obvious. It was shown by Fortuin and Oerlemans (1990) that a significant positive correlation $\left(r^{2}=0.61\right)$ exists between slope angle and temperature, being in our opinion the result of the break-down of the inversion through entrainment of warm air into the boundary layer. Because the relation between the katabatic wind and the inversion strength works both ways, we chose the surface slope as an independent and constant predictor.

In order to obtain a profile of drifting-snow transport, we used a simple parameterization that predicts the amount of drifting snow as a function of wind speed Equation (A3)). For annual mean wind speeds lower than $7 \mathrm{~m} \mathrm{~s}^{-1}$, a wind-speed distribution was fitted to the mean, after which the contributions to blowing snow for $V<6 \mathrm{~ms}^{-1}$ were omitted, which ensures a smooth transition towards zero transport in low wind-speed regions. The drifting-snow flux $Q$, as a function of $10 \mathrm{~m}$ wind speed, was developed by Budd (1966) (Fig. 15).

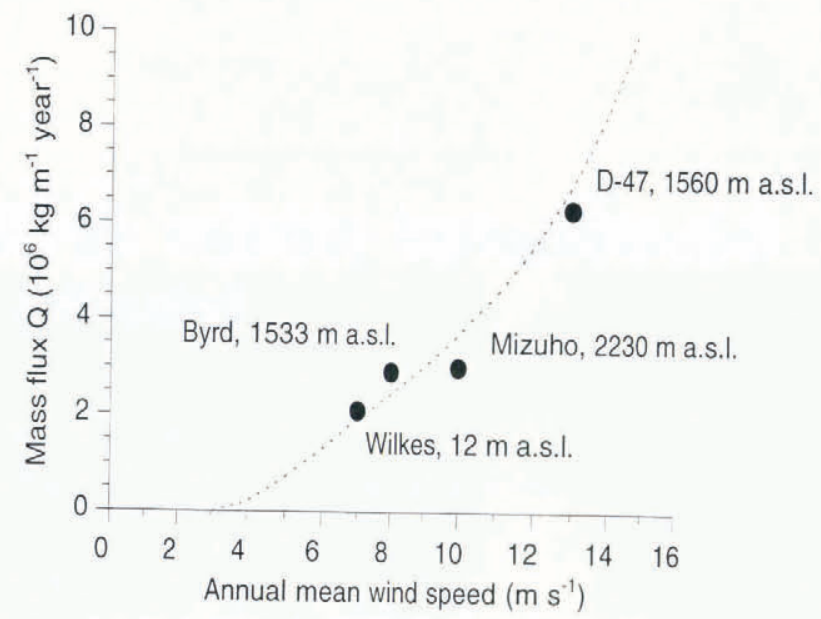

Fig. 15. Empirical wind-speed snowdrift relation
according to Budd (1966). Some observed
estimales, inserted in the figure, are taken from
Schwerdtfeger (1970), Kobayashi (1978) and
Wendler (1989).

Although drifting-snow physics is not well described by this equation (Schmidt, 1986), comparing it with the estimates of yearly drift rates of Kobayashi (1978) at Mizuho Station, Wendler (1989) at D-47 and other values taken from Schwerdtfeger (1970) yields reasonable agreement (Fig. 15). Before a snow particle is suspended in the air it has to be lifted from the surface by an upward velocity, for which the friction velocity is a scale not represented in Equation (A4). This threshold friction velocity is in the order of $0.15-0.22 \mathrm{~ms}^{-1}$ for relatively fresh snow, equivalent to a $10 \mathrm{~m}$ wind speed of $46 \mathrm{~m} \mathrm{~s}^{-1}$ in adiabatic conditions, applying a surface roughnes: length of $z_{0}=0.5 \mathrm{~mm}$. This threshold friction velocity will increase significantly for wind-hardened surfaces (Kind, 1981).

Equation (A4) predicts yearly mean surface temperature $T_{\mathrm{s}}(\mathrm{K})$ as a function of surface elevation $h_{\mathrm{s}}$ (kma.s.l.) and latitude ( $\left.{ }^{\circ} \mathrm{S}\right)$, while Equation (A5) predicts surface mass balance $\mathrm{MB}$ ( $\mathrm{cm}$ w.e.year ${ }^{-1}$ ) in terms of surface temperature $T_{\mathrm{s}}(\mathrm{K})$, surface slope $\alpha$ $\left(\mathrm{m} \mathrm{km}^{-1}\right)$ and surface shape $\partial \alpha / \partial x\left(\mathrm{~m} \mathrm{~km}^{-2}\right)$. They are taken from a statistical analysis by Fortuin and Oerlemans (1990) of $92710 \mathrm{~m}$ firn temperatures and 489 combined acumulation/temperature measurements. Equation (A4) was able to explain $81 \%$ of the variance and can therefore be considered reasonably accurate, but Equation (A5) only reproduced $40 \%$ of the mass-balance variation. It should therefore be regarded as a first-order estimate of the background mass balance. 